\title{
Prehl’ad krúžkovania vtákov na Slovensku za rok 2020
}

\author{
Bird-ringing results in Slovakia in 2020
}

\section{Michal JENČo \& Matej REPEL}

Slovenská ornitologická spoločnost'/BirdLife Slovensko, Krúžkovacia centrála, Námestie osloboditel'ov 1, SK-07101 Michalovce, Slovakia; e-mail: kruzkysk@gmail.com

\begin{abstract}
In 2020, 57 ringers ringed altogether 62,455 birds, of them 5,531 were nestlings. That number was 5\% $(2,984)$ higher compared to 2019. The ringed birds belonged to 161 species. The most numerous ringed species were Blackcap (Sylvia atricapilla, 7,681 ind.), Barn Swallow (Hirundo rustica, 7,536 ind.) Great Tit (Parus major, 6,109 individuals), Blue Tit (Cyanistes caeruleus, 5,463 ind.) and European robin (Erithacus rubecula, 4,704 ind.). Alltogether 710 abroad recoveries were registered, out of them were 293 individuals ringed abroad and re-trapped in Slovakia, 417 individuals ringed in Slovakia re-trapped abroad. The colour ringed schemes in Slovakia are presented here also.
\end{abstract}

Key words: bird ringing, recoveries, colour ringing schemes

\section{Úvod}

Táto správa zahŕňa všetky výsledky za rok 2020, ktoré krúžkovatelia spracovali a následne zaslali Krúžkovacej centrále (d’alej $\mathrm{KC}$ ). Krúžkovanie sa vykonávalo na základe rozhodnutí Ministerstva životného prostredia Slovenskej republiky o povolení výnimiek zo zákona č.543/2002 Z.z. o ochrane prírody a krajiny. Výnimka (rozhodnutie č.3320/2019-6.3 zo dňa 08.04.2019) oprávňuje na krúžkovanie všetkých druhov vtákov okrem vybraných druhov napr. niektorých sov, dravcov, volaviek a pod. Na základe výnimky (rozhodnutie č. 664/297/05-5.1 pil) sa umožňuje členom združenia Ochrana dravcov na Slovensku výskum dravcov a sov vrátane ich krúžkovania.

Celkovo evidujeme 89 krúžkovatel'ov spĺnajúcich kritériá pre udelenie licencie na krúžkovanie vtáctva a teda oprávnených využívat' výnimku. V roku 2020 skúšky úspešne absolvoval 1 krúžkovatel'. V roku 2020 využilo výnimku a vol’ne žijúce vtáky odchytávalo a okrúžkovalo 57 krúžkovatel'ov, ktorí zapísali svoje krúžkovacie údaje za rok 2020 do on-line databázy Rings. Ostatní krúžkovatelia avizovali, že v roku 2020 nekrúžkovali. Na stránke www.vtaky.sk zverejňujeme aktuálny zoznam krúžkovatel'ov oprávnených vykonávat' krúžkovatel'skú činnost' na základe výnimky spolu s prideleným typom licencie.

V roku 2020 sa krúžkovatelia zapojili do viacerých projektov (operačný program Životné prostredie, vedecko-výskumné projekty VEGA, projekty cezhraničnej spolupráce, LIFE projekty a i.). Išlo napríklad o krúžkovanie metodikou CES na 8 stacionároch (Drienovec, Gbelce, Dolné Vestenice, Kiarovský močiar, Senné, Slanica, Sabinov - strelnica a Bešeňová), zameranie na konkrétne druhy (napr. rybárik riečny, lastovička obyčajná). Ornitologický stacionár Drienovec je zaradený do medzinárodnej siete SEEN. Stále viac sa do popredia dostáva aj farebné značenie. Tento spôsob značenia je bez 
pochýb efektívnejším pri získavaní spätných hlásení než klasický spôsob.

$\mathrm{KC}$ funguje nad'alej s finančnou a materiálnou podporou SOS/BirdLife Slovensko v priestoroch kancelárie $\mathrm{v}$ Michalovciach pod vedením Mateja Repela a spolupracovníkom Michalom Jenčom. Väčšina krúžkovatel'ov vykonáva krúžkovanie na vlastné náklady a vo svojom vol'nom čase.

\section{Výsledky}

\section{Krúžkovanie}

V roku 2020 sa okrúžkovalo o 2984 vtákov viac ako v roku 2019 (59 472) - označených bolo spolu 62455 jedincov zo 162 druhov vtákov (151 druhov v 2019) (obr. 1, príloha 1). Z toho bolo 59481 spevavcov a 2975 nespevavcov. Najčastejšie krúžkovanými druhmi boli v roku 2020 Sylvia atricapilla, Hirundo rustica, Parus major, Cyanistes caeruleus a Erithacus rubecula (tab. 1). Medzi najpočetnejšie nespevavce patrili Ciconia ciconia, Falco tinnunculus, Circus aeruginosus (tab. 1). Označených bolo 5531 mlád'at. Najviac mlád’at bolo okrúžkovaných u druhu P. major, nasledovali $C$. ciconia, $F$. tinnunculus, Ficedula albicollis a Cinclus cinc-

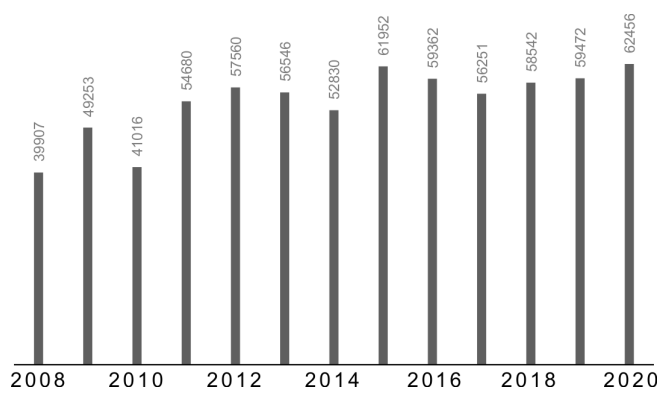

Obr. 1. Porovnanie počtu okrúžkovaných vtákov v rokoch 2008 - 2020 na Slovensku.

Fig. 1. Number of ringed birds in 2008-2020 in Slovakia.

lus (tab. 2). Graf nám ukazuje pozvol’ný nárast počtu okrúžkovaných vtákov za posledných 13 rokov (obr. 1); v posledných rokoch sledujeme vyrovnaný trend počtu krúžkovaných vtákov. Kompletné výsledky okrúžkovaných vtákov s počtom mlád'at a spätných hlásení sú v prílohe 1 . V roku 2020 bolo okrúžkovaných viac samcov (14 099) ako samíc (10 436); u 37921 jedincov nebolo možné určit' pohlavie.

Z hl'adiska vekového zloženia (obr. 2) majoritu tvorili vtáky v prvom roku života $(1 \mathrm{~K} ; 28$ 180), nasledujú, teda vtáky minimálne v druhom roku života a staršie $(+1 \mathrm{~K} ; 16311)$.

Tab. 1. Desat' najviac krúžkovaných druhov za rok 2020 na Slovensku.

Table 1. Ten most ringed species for 2020 in Slovakia.

\begin{tabular}{lclr}
\hline Spevavce / Passerines & Počet ex. / No. of ind. & Nespevavce / Non-passerines & Počet ex. / No. of ind. \\
\hline Sylvia atricapilla & 7682 & Ciconia ciconia & 1049 \\
Hirundo rustica & 7536 & Falco tinnunculus & 719 \\
Parus major & 6109 & Circus aeruginosus & 126 \\
Cyanistes caeruleus & 5463 & Falco cherrug & 92 \\
Erithacus rubecula & 4704 & Asio otus & 64 \\
Acrocephalus schoenobaenus & 2513 & Tyto alba & 61 \\
Phylloscopus collybita & 2290 & Corvus monedula & 41 \\
Prunella modularis & 1944 & Falco vespertinus & 35 \\
Carduelis spinus & 1512 & Bubo bubo & 27 \\
Acrocephalus scirpaceus & 1341 & Larus ridibundus & 25 \\
\hline
\end{tabular}

Tab. 2. Desat' najviac krúžkovaných druhov na hniezde (pull.) v roku 2020 na Slovensku.

Table 2. Ten most ringed species on the nest for 2020 in Slovakia.

\begin{tabular}{lclc}
\hline Spevavce / Passerines & Počet ex. / No. of ind. & Nespevavce / Non-passerines & Počet ex. / No. of ind. \\
\hline Parus major & 1108 & Ciconia ciconia \\
Ficedula albicollis & 544 & Falco tinnunculus \\
Cinclus cinclus & 351 & Circus aeruginosus \\
Parus caeruleus & 306 & Falco cherrug & 125 \\
Hirundo rustica & 285 & Apus apus & 91 \\
Acrocephalus arundinaceus & 113 & Tyto alba & Corvus monedula \\
Phoenicurus ochruros & 112 & Falco vespertinus \\
Sturnus vulgaris & 62 & Bubo bubo \\
Passer montanus & 56 & Asio otus \\
Sitta europaea & 56 & 35 \\
\hline
\end{tabular}




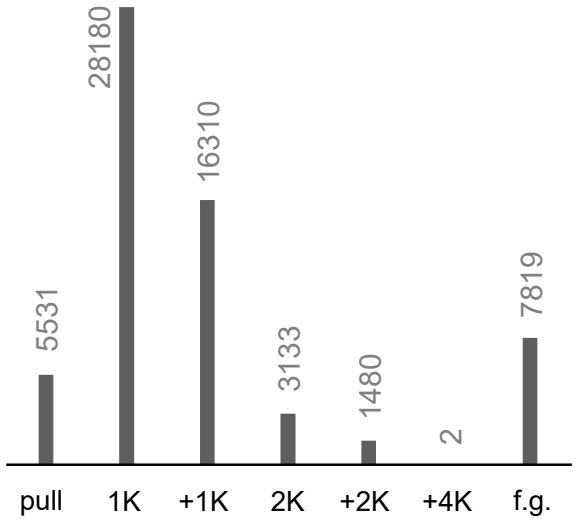

Obr. 2. Podiel vekových kategórií okrúžkovaných vtákov. (pull. - mlád'atá, f.g. - plne vyvinuté, $1 K-1$. kalendárny rok života, $+1 K-$ starší ako v 1. kalendárnom roku života, $2 K-v$ 2. kalendárnom roku života, $+2 K-$ starši ako v 2. roku života) Fig. 2. Age categories of the ringed birds in the age categories (pull. - young, f.g. - full grown, $1 K-1$ st calendar year $+1 K$ - older than 1 st calendar year, $2 K-2 n d$ calendar year, $+2 K-$ older than 2 nd calendar year).

\section{Spätné hlásenia}

V roku 2020 sa zaevidovalo spolu 6997 spätných hlásení z 92 druhov. Z toho 6289 hlásení bolo domácich v rámci Slovenska. Medzi 10 najčastejšie retrapovaných druhov sa dostalo 9 spevavcov a C. ciconia (284) (príloha 1). V evidencii sa nachádza 293 tzv. „C“ hlásení, „cudzie“"vtáky krúžkované v zahraničí a odčítané resp. odchytené na území Slovenska. Už tradične najviac vtákov sa identifikovalo s mad'arskými krúžkami a to až v 131 prípadoch (tab. 3). Druhou krajinou bolo Pol'sko s 78 krúžkovancami. Prvú trojicu uzatvára Česko s 31 krúžkovancami. Úzko to súvisí s geografickou polohou, ale aj špičkovou spoluprácou s týmito centrálami, kde dochádza $\mathrm{k}$ takmer okamžitej výmene údajov. Spolu sa na Slovensku podarilo identifikovat' vtáky zo 14 krajín. Za rok 2020 KC eviduje 417 ,Z“ hlásení. Sú to jedince krúžkované na našom území a odčítané resp. odchytené v niektorej inej krajine. Najviac hlásení zaslali kolegovia z Mad'arska (212), nasleduje Pol'sko (68) a Česká republika (44). Hlásenia o Slovenských krúžkovancoch pochádzajú z 24 krajín (tab. 3).

Spätné hlásenia boli získané za 31 rôznych okolností nálezu vtáka (tab. 4). Najčastejšie
Tab. 3. Zahraničné spätné hlásenia za rok 2020 (Z-slovenský krúžkovanec zaznamenaný v zahraničí , C - vták krúžkovaný $v$ zahraničí zaznamenaný na Slovensku).

Table 3. Foreign recoveries in 2020 ( $Z$ - bird ringed in Slovakia recovered abroad, $\mathrm{C}$ - bird ringed abroad recovered in Slovakia).

\begin{tabular}{llrr}
\hline Krajina / Country & Z & C \\
\hline HGB & Mad'arsko & 212 & 131 \\
PLG & Pol'sko & 68 & 78 \\
CZP & Česko & 44 & 31 \\
DE & Nemecko & 30 & 11 \\
AUW & Rakúsko & 17 & 12 \\
HES & Švajčiarsko & 7 & \\
NLA & Holandsko & 6 & \\
SIL & Slovinsko & 5 & 1 \\
FRP & Francúzsko & 4 & 1 \\
SFH & Fínsko & 3 & 7 \\
IAB & Taliansko & 3 & 4 \\
ROB & Rumunsko & 3 & \\
BL & Bulharsko & 2 & \\
RSB & Srbsko & 2 & \\
TUA & Turecko & 2 & \\
ABT & Albánsko & 1 & \\
BYM & Bielorusko & 1 & 3 \\
HRZ & Chorvátsko & 1 & 10 \\
GRA & Grécko & 1 & \\
KE & Keňa & 1 & \\
MZ & Mozambik & 1 & \\
RUM & Rusko & 1 & 1 \\
ZA & JAR & 1 & \\
UKK & Ukrajina & 1 & \\
LTK & Litva & & \\
SVS & Švédsko & & \\
\hline Spolu / Total & 417 & 293 \\
\hline
\end{tabular}

boli vtáky odchytené (6149 jedincov), podl'a farebného krúžku bolo identifikovaných 374 jedincov. Ornitologický krúžok bol odčítaný bez chytenia vtáka u 292 jedincov (tab. 4).

\section{Pod'akovanie}

Pod'akovanie patrí všetkým, ktorí si splnili svoju povinnost' a v stanovenom čase zaslali výsledky z krúžkovania spracované v programe RINGS čím umožnili spracovanie nielen tejto správy. Ďakujeme mnohým slovenským a zahraničným nálezcom a pozorovatel'om, ktorí zaslali údaje o spätných hláseniach a za spoluprácu všetkým zahraničným krúžkovacím centrálam. Ďakujeme aj koordinátorom programov farebného značenia za pomoc a koordináciu.

Došlo: 4. 11. 2021

Prijaté: 13. 12. 2021

Online: 21. 12. 2021 
Tab. 4. Okolnosti nálezu vtákov pri spätných hláseniach na našom území.

Table 4. Finding circumstances of birds in Slovakia. Finding circumstances - code $=$ name: $00=$ Found, $01=$ Bird found, $02=$ Ring only found, $03=$ Leg \& ring only found, $08=$ Ringing casualty, $09=$ Ring caused recovery, $10=$ Shot, $20=$ Intentionally taken, 27 = At nestbox/artificial site, $28=$ Metal ring read in field, $29=$ Colour mark record, $35=$ Electrocuted, $37=$ Poisoned: poison identified , $38=$ Poisoned: poison not identified, $40=$ Road casualty, $43=$ Hit wires, $44=$ Hit glass, $45=$ Hit man-made structure, 50 = Injured, $51=$ Malformation, $60=$ Taken by animal, $61=$ Taken by cat, $64=$ Taken by owl or raptor, $65=$ Taken by predatory bird, $66=$ Taken by bird, $67=$ Taken by a conspecific, $81=$ Identified from leg ring(s), $82=1$ dentified from neck ring(s), $83=$ Identified from wing tags, $85=$ Identified with satellite tracking, $87=$ Identified from nasal tags.

\begin{tabular}{|c|c|c|}
\hline Kód / Code & Okolnosti nálezu vtáka / Finding circumstances of bird & Počet jedincov / No. of ind. \\
\hline$\overline{00}$ & Nájdený, bez bližších údajov & 5 \\
\hline 01 & nájdený mítvy & 33 \\
\hline 02 & nájdený iba krúžok & 3 \\
\hline 03 & Nájdená iba noha s krúžkom & 5 \\
\hline 08 & Mŕtvy alebo zranený pri odchyte, krúžkovaní & 7 \\
\hline 09 & zranenie alebo úhyn spôsobený krúžkom & 1 \\
\hline 10 & Strelený & 3 \\
\hline 20 & chytený & 6149 \\
\hline 27 & Nájdený mítvy v búdke & 1 \\
\hline 28 & kovový krúžok odčítaný bez chytenia vtáka & 292 \\
\hline 29 & Identifikácia na základe farebnej značky & 22 \\
\hline 35 & Zasiahnutý elektrickým prúdom & 28 \\
\hline 37 & Otrávený známou chemickou látkou & 1 \\
\hline 38 & Otrávený neznámou chemickou látkou & 1 \\
\hline 40 & Nájdený na ceste, zrazený autom & 5 \\
\hline 43 & náraz na drôty & 3 \\
\hline 44 & náraz na sklo & 2 \\
\hline 45 & náraz na budovu, most a pod. & 1 \\
\hline 50 & Zranenie nezavinené človekom & 1 \\
\hline 51 & Znetvorenie (zlomený zobák, nádor a pod.) & 1 \\
\hline 60 & Chytený neurčeným živočíchom & 5 \\
\hline 61 & Chytený mačkou & 5 \\
\hline 64 & Chytený sovou alebo dravcom & 1 \\
\hline 65 & Chytený neznámou sovou alebo dravcom & 1 \\
\hline 66 & Chytený iným druho vtáka & 1 \\
\hline 67 & Chytený určitým dravcom & 3 \\
\hline 81 & Identifikácia podla farebných krúžkov & 374 \\
\hline 82 & Identifikácia podl’a límca & 63 \\
\hline 83 & identifikácia podl'a krídlovej značky & 1 \\
\hline 85 & Identifikácia podl'a satelitnej vysielačky & 4 \\
\hline 87 & Identifikácia podla nosnej značky & 1 \\
\hline
\end{tabular}


Príloha 1. Súhrnné výsledky krúžkovania vtákov na Slovensku v r. 2020 (pull. - mlád’atá, f.g. - plne vyvinuté, D\% - dominancia krúžkovaných druhov, SH - spätné hlásenia zahŕňajúce len vtáky krúžkované slovenskými krúžkami - tzv. hlásenia „A“ a „Z“). Desat' najviac znovu odchytených druhov v roku 2020 na Slovensku je označených horným indexom 1 - 10.

Appendix 1. Summary bird ringing in Slovakia in 2020 (pull. - young, f.g. - full grown, D\% - ringed birds species dominance, $\mathrm{SH}$ - recoveries including only birds with Slovak rings, i.e. so-called "A“ and "Z" recoveries). Ten most retrapped species for 2020 in Slovakia is marked with superscript 1-10.

\begin{tabular}{|c|c|c|c|c|c|}
\hline Druh / Species & pull. & f.g. & $\sum$ & $\mathrm{D} \%$ & $\mathrm{SH}$ \\
\hline Sylvia atricapilla ${ }^{4}$ & 0 & 7681 & 7681 & 12,30 & 527 \\
\hline Hirundo rustica ${ }^{7}$ & 285 & 7251 & 7536 & 12,07 & 155 \\
\hline Parus major ${ }^{1}$ & 1108 & 5001 & 6109 & 9,78 & 1348 \\
\hline Parus caeruleus ${ }^{3}$ & 306 & 5157 & 5463 & 8,75 & 718 \\
\hline Erithacus rubecula ${ }^{2}$ & 0 & 4704 & 4704 & 7,53 & 1192 \\
\hline Acrocephalus schoenobaenus & 0 & 2513 & 2513 & 4,02 & 85 \\
\hline Phylloscopus collybita ${ }^{10}$ & 0 & 2290 & 2290 & 3,67 & 109 \\
\hline Prunella modularis & 0 & 1944 & 1944 & 3,11 & 91 \\
\hline Carduelis spinus & 0 & 1512 & 1512 & 2,42 & 53 \\
\hline Acrocephalus scirpaceus ${ }^{6}$ & 0 & 1341 & 1341 & 2,15 & 174 \\
\hline Regulus regulus & 0 & 1271 & 1271 & 2,04 & 94 \\
\hline Carduelis carduelis & 0 & 1089 & 1089 & 1,74 & 73 \\
\hline Ciconia ciconia ${ }^{5}$ & 1040 & 9 & 1049 & 1,68 & 284 \\
\hline Carduelis chloris & 0 & 818 & 818 & 1,31 & 39 \\
\hline Acrocephalus palustris & 5 & 810 & 815 & 1,30 & 51 \\
\hline Serinus serinus & 3 & 728 & 731 & 1,17 & 26 \\
\hline Falco tinnunculus & 667 & 52 & 719 & 1,15 & 16 \\
\hline Sylvia communis & 0 & 707 & 707 & 1,13 & 51 \\
\hline Ficedula albicollis & 544 & 128 & 672 & 1,08 & 32 \\
\hline Fringilla coelebs & 0 & 669 & 669 & 1,07 & 16 \\
\hline Turdus merula ${ }^{8}$ & 16 & 598 & 614 & 0,98 & 155 \\
\hline Anthus trivialis & 0 & 597 & 597 & 0,96 & 0 \\
\hline Riparia riparia & 0 & 589 & 589 & 0,94 & 68 \\
\hline Emberiza schoeniclus & 0 & 589 & 589 & 0,94 & 51 \\
\hline Troglodytes troglodytes & 0 & 570 & 570 & 0,91 & 83 \\
\hline Phylloscopus trochilus & 0 & 550 & 550 & 0,88 & 17 \\
\hline Sylvia borin & 0 & 514 & 514 & 0,82 & 42 \\
\hline Coccothraustes coccothraustes & 0 & 503 & 503 & 0,81 & 22 \\
\hline Sylvia curruca & 0 & 436 & 436 & 0,70 & 42 \\
\hline Cinclus cinclus & 351 & 36 & 387 & 0,62 & 6 \\
\hline Acrocephalus arundinaceus & 113 & 272 & 385 & 0,62 & 33 \\
\hline Aegithalos caudatus & 0 & 378 & 378 & 0,61 & 105 \\
\hline Turdus philomelos & 0 & 378 & 378 & 0,61 & 23 \\
\hline Passer montanus & 56 & 318 & 374 & 0,60 & 17 \\
\hline Phoenicurus ochruros & 112 & 223 & 335 & 0,54 & 16 \\
\hline Sturnus vulgaris & 62 & 236 & 298 & 0,48 & 0 \\
\hline Carduelis flammea cabaret & 0 & 243 & 243 & 0,39 & 2 \\
\hline Remiz pendulinus & 0 & 241 & 241 & 0,39 & 20 \\
\hline Pyrrhula pyrrhula & 0 & 237 & 237 & 0,38 & 21 \\
\hline Parus palustris & 0 & 234 & 234 & 0,37 & 108 \\
\hline Locustella luscinioides & 0 & 234 & 234 & 0,37 & 43 \\
\hline Luscinia megarhynchos & 0 & 224 & 224 & 0,36 & 47 \\
\hline Lanius collurio & 0 & 220 & 220 & 0,35 & 10 \\
\hline Parus ater & 32 & 165 & 197 & 0,32 & 17 \\
\hline Emberiza citrinela & 5 & 183 & 188 & 0,30 & 30 \\
\hline Motacilla flava & 0 & 188 & 188 & 0,30 & 1 \\
\hline Sitta europaea & 56 & 101 & 157 & 0,25 & 59 \\
\hline Regulus ignicapillus & 0 & 153 & 153 & 0,24 & 11 \\
\hline Circus aeruginosus & 125 & 1 & 126 & 0,20 & 3 \\
\hline Motacilla alba & 14 & 110 & 124 & 0,20 & 0 \\
\hline Carduelis flammea flammea & 0 & 123 & 123 & 0,20 & 0 \\
\hline Passer domesticus & 5 & 115 & 120 & 0,19 & 3 \\
\hline Panurus biarmicus & 0 & 97 & 97 & 0,16 & 59 \\
\hline Muscicapa striata & 4 & 90 & 94 & 0,15 & 4 \\
\hline Falco cherrug & 91 & 1 & 92 & 0,15 & 3 \\
\hline Carduelis cannabina & 10 & 82 & 92 & 0,15 & 0 \\
\hline Jynx torquilla & 40 & 45 & 85 & 0,14 & 3 \\
\hline Fringilla montifringilla & 0 & 81 & 81 & 0,13 & 0 \\
\hline Dendrocopos major & 0 & 80 & 80 & 0,13 & 22 \\
\hline Delichon urbica & 7 & 71 & 78 & 0,12 & 0 \\
\hline Apus apus & 67 & 8 & 75 & 0,12 & 1 \\
\hline Alcedo atthis & 0 & 73 & 73 & 0,12 & 16 \\
\hline Asio otus & 25 & 39 & 64 & 0,10 & 0 \\
\hline Tyto alba & 55 & 6 & 61 & 0,10 & 4 \\
\hline Hippolais icterina & 0 & 54 & 54 & 0,09 & 0 \\
\hline
\end{tabular}


Príloha 1. Pokračovanie.

Appendix 1. Continuation.

\begin{tabular}{|c|c|c|c|c|c|}
\hline Druh / Species & pull. & f.g. & $\Sigma$ & $\mathrm{D} \%$ & $\mathrm{SH}$ \\
\hline Phoenicurus phoenicurus & 0 & 54 & 54 & 0,09 & 0 \\
\hline Certhia familiaris & 0 & 50 & 50 & 0,08 & 42 \\
\hline Motacilla cinerea & 28 & 21 & 49 & 0,08 & 0 \\
\hline Garrulus glandarius & 1 & 47 & 48 & 0,08 & 4 \\
\hline Locustella naevia & 0 & 43 & 43 & 0,07 & 2 \\
\hline Carduelis flammea flammea/cabaret & 0 & 43 & 43 & 0,07 & 0 \\
\hline Phylloscopus sibilatrix & 0 & 43 & 43 & 0,07 & 0 \\
\hline Corvus monedula & 40 & 1 & 41 & 0,07 & 0 \\
\hline Merops apiaster & 0 & 37 & 37 & 0,06 & 5 \\
\hline Sylvia nisoria & 0 & 37 & 37 & 0,06 & 1 \\
\hline Ficedula hypoleuca & 0 & 37 & 37 & 0,06 & 0 \\
\hline Falco vespertinus & 35 & 0 & 35 & 0,06 & 65 \\
\hline Parus cristatus & 0 & 34 & 34 & 0,05 & 13 \\
\hline Locustella fluviatilis & 0 & 30 & 30 & 0,05 & 4 \\
\hline Turdus pilaris & 0 & 30 & 30 & 0,05 & 0 \\
\hline Ixobrychus minutus & 0 & 28 & 28 & 0,04 & 10 \\
\hline Parus montanus & 0 & 28 & 28 & 0,04 & 6 \\
\hline Bubo bubo & 27 & 0 & 27 & 0,04 & 0 \\
\hline Larus ridibundus & 24 & 1 & 25 & 0,04 & 19 \\
\hline Saxicola torquata & 0 & 24 & 24 & 0,04 & 1 \\
\hline Aquila heliaca & 23 & 0 & 23 & 0,04 & 9 \\
\hline Gallinago gallinago & 0 & 23 & 23 & 0,04 & 0 \\
\hline Upupa epops & 20 & 3 & 23 & 0,04 & 0 \\
\hline Luscinia Iuscinia & 0 & 22 & 22 & 0,04 & 13 \\
\hline Buteo buteo & 6 & 16 & 22 & 0,04 & 0 \\
\hline Cygnus olor & 2 & 18 & 20 & 0,03 & 15 \\
\hline Falco peregrinus & 20 & 0 & 20 & 0,03 & 3 \\
\hline Saxicola rubetra & 0 & 19 & 19 & 0,03 & 0 \\
\hline Turdus iliacus & 0 & 17 & 17 & 0,03 & 0 \\
\hline Ardea cinerea & 16 & 0 & 16 & 0,03 & 1 \\
\hline Ficedula parva & 0 & 16 & 16 & 0,03 & 1 \\
\hline Tringa glareola & 0 & 16 & 16 & 0,03 & 0 \\
\hline Aquila pomarina & 15 & 0 & 15 & 0,02 & 8 \\
\hline Athene noctua & 13 & 2 & 15 & 0,02 & 0 \\
\hline Porzana porzana & 0 & 15 & 15 & 0,02 & 0 \\
\hline Dendrocopos medius & 0 & 14 & 14 & 0,02 & 5 \\
\hline Accipiter nisus & 0 & 14 & 14 & 0,02 & 2 \\
\hline Otus scops & 0 & 13 & 13 & 0,02 & 1 \\
\hline Emberiza cia & 0 & 12 & 12 & 0,02 & 2 \\
\hline Strix aluco & 8 & 4 & 12 & 0,02 & 0 \\
\hline Columba palumbus & 8 & 3 & 11 & 0,02 & 1 \\
\hline Caprimulgus europaeus & 0 & 11 & 11 & 0,02 & 0 \\
\hline Haliaeetus albicilla & 10 & 0 & 10 & 0,02 & 6 \\
\hline Picus viridis & 0 & 10 & 10 & 0,02 & 0 \\
\hline Streptopelia decaocto & 0 & 10 & 10 & 0,02 & 0 \\
\hline Anthus pratensis & 0 & 9 & 9 & 0,01 & 0 \\
\hline Circus pygargus & 9 & 0 & 9 & 0,01 & 0 \\
\hline Oriolus oriolus & 0 & 9 & 9 & 0,01 & 0 \\
\hline Dendrocopos minor & 0 & 8 & 8 & 0,01 & 2 \\
\hline Crex crex & 0 & 8 & 8 & 0,01 & 0 \\
\hline Picus canus & 0 & 8 & 8 & 0,01 & 0 \\
\hline Aquila chrysaetos & 7 & 0 & 7 & 0,01 & 1 \\
\hline Luscinia svecica cyanecula & 0 & 6 & 6 & 0,01 & 3 \\
\hline Hirundo rustica $\times$ Delichon urbica & 5 & 0 & 5 & 0,01 & 0 \\
\hline Corvus frugilegus & 4 & 0 & 4 & 0,01 & 0 \\
\hline Phylloscopus inornatus & 0 & 4 & 4 & 0,01 & 0 \\
\hline Rallus aquaticus & 0 & 4 & 4 & 0,01 & 0 \\
\hline Lanius excubitor & 0 & 3 & 3 & 0,00 & 1 \\
\hline Tetrao urogallus & 0 & 3 & 3 & 0,00 & 1 \\
\hline Accipiter gentilis & 0 & 3 & 3 & 0,00 & 0 \\
\hline Acrocephalus melanopogon & 0 & 3 & 3 & 0,00 & 0 \\
\hline Anas clypeata & 3 & 0 & 3 & 0,00 & 0 \\
\hline Falco subbuteo & 0 & 3 & 3 & 0,00 & 0 \\
\hline Gallinula chloropus & 0 & 3 & 3 & 0,00 & 0 \\
\hline Lymnocryptes minimus & 0 & 3 & 3 & 0,00 & 0 \\
\hline Pica pica & 0 & 3 & 3 & 0,00 & 0 \\
\hline Anthus spinoletta & 0 & 2 & 2 & 0,00 & 0 \\
\hline Asio flammeus & 0 & 2 & 2 & 0,00 & 0 \\
\hline Dendrocopos syriacus & 0 & 2 & 2 & 0,00 & 0 \\
\hline
\end{tabular}


Príloha 1. Pokračovanie.

Appendix 1. Continuation.

\begin{tabular}{|c|c|c|c|c|c|}
\hline Druh / Species & pull. & f.g. & $\Sigma$ & $\mathrm{D} \%$ & $\mathrm{SH}$ \\
\hline Emberiza pusilla & 0 & 2 & 2 & 0,00 & 0 \\
\hline Loxia curvirostra & 0 & 2 & 2 & 0,00 & 0 \\
\hline Luscinia svecica & 0 & 2 & 2 & 0,00 & 0 \\
\hline Philomachus pugnax & 0 & 2 & 2 & 0,00 & 0 \\
\hline Strix uralensis & 0 & 2 & 2 & 0,00 & 0 \\
\hline Tringa nebularia & 0 & 2 & 2 & 0,00 & 0 \\
\hline Turdus viscivorus & 0 & 2 & 2 & 0,00 & 0 \\
\hline Larus cachinnans $^{9}$ & 1 & 0 & 1 & 0,00 & 135 \\
\hline Pluvialis apricaria & 0 & 1 & 1 & 0,00 & 1 \\
\hline Anas crecca & 0 & 1 & 1 & 0,00 & 0 \\
\hline Anthus cervinus & 0 & 1 & 1 & 0,00 & 0 \\
\hline Botaurus stellaris & 1 & 0 & 1 & 0,00 & 0 \\
\hline Calidris alpina & 0 & 1 & 1 & 0,00 & 0 \\
\hline Carduelis flavirostris & 0 & 1 & 1 & 0,00 & 0 \\
\hline Carpodacus erythrinus & 0 & 1 & 1 & 0,00 & 0 \\
\hline Certhia brachydactyla & 0 & 1 & 1 & 0,00 & 0 \\
\hline Columba oenas & 1 & 0 & 1 & 0,00 & 0 \\
\hline Cuculus canorus & 0 & 1 & 1 & 0,00 & 0 \\
\hline Charadrius hiaticula & 0 & 1 & 1 & 0,00 & 0 \\
\hline Lyrurus tetrix & 0 & 1 & 1 & 0,00 & 0 \\
\hline Miliaria calandra & 0 & 1 & 1 & 0,00 & 0 \\
\hline Oenanthe oenanthe & 0 & 1 & 1 & 0,00 & 0 \\
\hline Pernis apivorus & 0 & 1 & 1 & 0,00 & 0 \\
\hline Phylloscopus collybita tristis & 0 & 1 & 1 & 0,00 & 0 \\
\hline Scolopax rusticola & 0 & 1 & 1 & 0,00 & 0 \\
\hline Streptopelia turtur & 0 & 1 & 1 & 0,00 & 0 \\
\hline Vanellus vanellus & 0 & 1 & 1 & 0,00 & 0 \\
\hline Anser anser & 0 & 0 & 0 & 0,00 & 12 \\
\hline Ciconia nigra & 0 & 0 & 0 & 0,00 & 6 \\
\hline Corvus corax & 0 & 0 & 0 & 0,00 & 1 \\
\hline Nycticorax nycticorax & 0 & 0 & 0 & 0,00 & 1 \\
\hline$\sum$ & 5531 & 56924 & 62455 & 100 & 6704 \\
\hline
\end{tabular}

